provision, even if it does not entirely remove the evil of a permanent loss in population, will at least lessen the numbers of those who do not return to their homes after a period of extra-territorial employment. A further important provision sets up a standing committee of representatives of the three Governments to secure co-ordination and to consider problems in connexion with the supply of labour as they arise.

\section{Population Investigation Committee}

IT is announced in The Times of November 5 that a committee has been formed to investigate the fall in the birth-rate in Great Britain and its probable consequences. The committee, which has been appointed by the council of the Eugenics Society, is presided over by Prof. A. M. Carr-Saunders, and has among its members, Lord Horder, Mrs. Hubback, Dr. Julian Huxley, Prof. L. Hogben, Dr. R. R. Kuczynski, Lady (Rhys) Williams, Prof.J. Young, and other authorities on various aspects of the subject. Dr. C. P. Blacker, the general secretary of the Eugenics Society, is honorary secretary of the Committee, and Mr. D. V. Glass is research secretary. $\mathrm{Mr}$. Glass has recently published a useful book on this subject, entitled "The Struggle for Population". The committee has already held two meetings, and its investigations are gradually taking shape. The main object is, in the first place, to ascertain the facts of the case and the causes of the decline in the number of births per family; and for this purpose it invites the co-operation of institutions and individuals engaged upon relevant lines of research. Inquiries may be addressed to the Secretary, Population Investigation Committee, 69 Eccleston Square, London, S.W.l.

\section{New Discharge Bulb Lamps}

THE new discharge bulb lamps are already in use on the Continent, and judging from the fact that they were shown at a meeting of the Illuminating Engineering Society on October 13, they will probably be soon on sale in Great Britain. In appearance, they are like the ordinary 'pearl' lamp but they have no filament. They contain a small quartz mercury vapour discharge lamp "about the size of half a cigarette" and they are corrected for colour. Internally the bulb is coated with a fluorescent powder, in the same way as the lower area of the inside of the cathode ray tube, where the picture is shown in television reception. According to the Electrical Contractor of November, the lamps are available in two sizes, 80 watts and 125 watts. The light output of these lamps is about 40 lumens per watt. This compares with the 12 lumens per watt of the ordinary coiled-coil incandescent lamp. The life is stated to be about 1,500 hours. The 'colour correction' of these lamps is effected by the fluorescent powder used. The human complexion when illuminated by the lamps shown at the meeting was very little altered, the change being scarcely noticeable. Owing to the fact that the internal film transforms the invisible ultra-violet light emitted by the mercury vapour lamp into light of visible wave-length, the loss of light by the absorption of the bulb is compensated for by this fluorescence. No details are yet available as to the price of the lamp, but we seem to be on the eve of a new development in house lighting.

\section{Recent Acquisitions at the Science Museum}

THE Oxford heliometer of 1848 has been placed on exhibition in the Astronomy Collection (Gallery LXIV). This instrument was made for the Radcliffe Observatory, Oxford, by Messrs. A. and G. Repsold of Hamburg on the advice of the famous German astronomer F. W. Bessel, who had in 1838 with a similar instrument obtained the first satisfactory measure of the parallax of a fixed star. The distance of the star, 61 Cygni, was found to be some 400,000 times the sun's distance of $93,000,000$ miles. The Oxford heliometer was for many years one of the most powerful and accurate instruments of its kind in the world. It is notable among other things for the first application of electrical illumination to an astronomical instrument. It was dismounted and taken to pieces in 1906, and so remained until its removal in 1935 to the Science Museum, where it has been renovated and set up as it was originally, a striking testimony to the nineteenth century instrument maker's art. In the Chemistry Collection (Gallery LXVI), an original tube of the metal rhodium prepared by its discoverer, Dr. William Hyde Wollaston, about 1825 has been placed on exhibition. Rhodium has recently become of interest as a nontarnishing substitute for silver in electroplating.

\section{Zoological Survey of India}

THE report of the Zoological Survey of India, recently issued, covers the years 1932-35, coinciding with a period of retrenchment in civil expenditure and consequent restriction of activities. It records the retirement of Lieut.-Colonel R. B. Seymour Sewell in 1933, and his subsequent extensive biological investigations as leader of the Murray Oceanographical Expedition to the Indian Ocean, and is written by his successor, Dr. Baini Prashad. The investigations of the Survey include detailed work upon the Trochus shell fisheries of the Andaman Islands; identification of animals of economic importance from the medical or sanitary point of view, carried out for various institutions and public bodies ; identification of human and animal remains excavated at various chalcolithic sites in Sind; and anthropological work connected with the census. Unfortunately, the abolition of the post of zoological collector and the necessity of restricting expenditure has greatly reduced the field-collecting and observations which used to be so desirable and characteristic an activity of the Survey.

\section{Bibliography of Seismology}

The last two quarterly numbers of the "Bibliography of Seismology" prepared by Mr. E. A. Hodgson and printed in the Publications of the Dominion Observatory, Ottawa (12, 159, 181 ; 